\title{
Proportion of Family Physicians Providing Maternity Care Continues to Decline
}

\author{
Sebastian T. C. Tong, BA, Laura A. Makaroff, DO, Imam M. Xierali, PhD, \\ Parwen Parhat, MA, James C. Puffer, MD, Warren P. Newton, MD, MPH, \\ and Andrew W. Bazemore, MD, MPH
}

\begin{abstract}
Family physicians traditionally have played an integral role in delivering babies as a component of the comprehensive care they provide for women. The proportion of family physicians who report providing any maternity care continues to decrease. This trend is particularly concerning because family physicians are the most widely distributed specialty and are essential to bealth care access in rural areas. (J Am Board Fam Med 2012;25:270-271.)
\end{abstract}

As a specialty that provides comprehensive care, family medicine encompasses all aspects of women's health, including maternity care. Access to regular prenatal care and labor and delivery services are essential in preventing poor perinatal outcomes and improving early childhood development. Several studies over the past decade have reported declining contributions to maternity care by family physicians. ${ }^{1,2}$

Seeking to update past findings, we analyzed data from a census of the American Board of Family Medicine diplomates who were applying for the Maintenance of Certification for Family Physicians examination during the years 2000 to 2010 ( $\mathrm{n}=$ 7436, 8021, 9223, 9241, 9400, 7755, 8216, 9409, 9551,9536 , and 2433 , respectively) to determine the mean percentage of practice time spent in maternity care across the study years and the percentage of family physicians who report providing any maternity care in each given year. The proportion of US family physicians who report providing maternity care declined from $23.3 \%$ in 2000 to $9.7 \%$

This article was externally peer reviewed.

Submitted 26 August 2011; revised 20 October 2011; accepted 14 November 2011.

From the Boston University School of Medicine, Brookline, MA (STCT), The Robert Graham Center, Washington, DC (LAM, IMX, AWB); George Mason University, Fairfax, VA (PP); The American Board of Family Medicine, Lexington, KY (JCP); and the University of North Carolina School of Medicine, Chapel Hill (WPN).

Funding: none.

Conflict of interest: none declared.

Corresponding author: Sebastian T. C. Tong, BA, Lawrence Family Medicine Residency, 34 Haverhill Street, Lawrence, MA 01841 (E-mail: sebastian.tc.tong@gmail.com). in 2010 (Figure 1). Of the family physicians who do provide maternity care, $10.1 \%$ of their time, on average (aggregated over 2000 to 2010), was spent doing so.

All family physicians are trained to provide maternity care; however, few report providing this care. Access to maternity care in rural and underserved communities, which is disproportionately provided by family physicians, is threatened. ${ }^{3}$ The decline in the maternity care provision by family physicians may signal an alarming overall decline in the scope of practice of family physicians. ${ }^{4}$ With malpractice costs, lifestyle concerns, lack of institutional and community support of family physicians delivering babies, and proposed changes to Residency Review Committee Family Medicine requirements, this proportion may continue to de-

Figure 1. Declining percent of family physicians providing maternity care. Source: American Board of Family Medicine Examination Application.

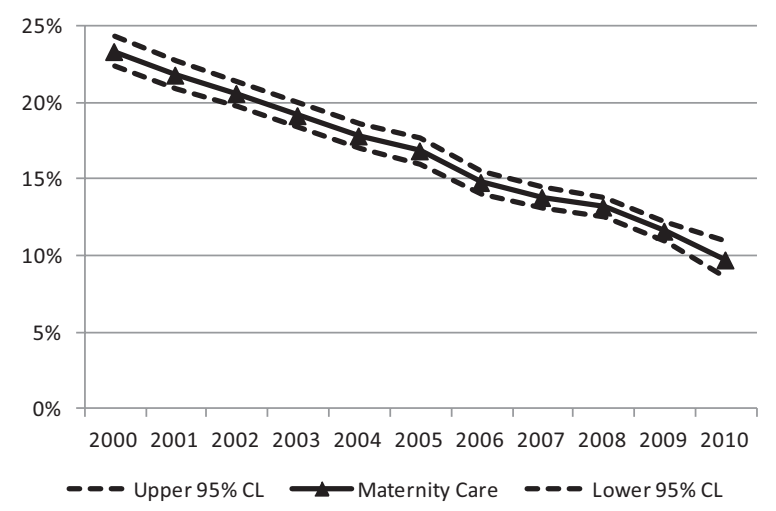


cline unless policies are put in place to encourage family physician provision of maternity care.

\section{References}

1. Cohen D, Coco A. Declining trends in the provision of prenatal care visits by family physicians. Ann Fam Med 2009;7:128-33.

2. Guirguis-Blake J, Fryer GE, Deutchman M, Green LA, Dovey SM, Phillips RL. Family physicians' de- clining contribution to prenatal care in the United States. Am Fam Physician 2002;66:2192.

3. Chen FM, Huntington J, Kim S, Phillips WR, Stevens NG. Prepared but not practicing: declining pregnancy care among recent family medicine residency graduates. Fam Med 2006;38:423-6.

4. Barr WB. Why pregnancy care should be an essential part of family medicine training. Fam Med 2005; 37:364-6. 